As Fig. 2 indicates, for both groups the removal of the surround reduced the level of responding: for houselight off, $F(1,11)=36.69$; for houselight on, $\mathrm{F}(1,11)=15.43$; both $\mathrm{p}<.01$. For the houselight-off group there was a somewhat sharper absolute gradient under the black background condition; however, the interaction between stimuli and background was not significant. Thus, masking was significant only with the relative generalization measure.

The arguments favoring relative generalization gradients as a more valid index of stimulus control than absolute gradients have been made elsewhere and need not be repeated here (e.g., Thomas \& King, 1959; Thomas, Freeman, Svinicki, Burr, \& Lyons, 1970; Thomas, Burr, \& Eck, 1970). Usually comparisons of absolute or of relative gradients are in essential agreement with regard to the effects of a particular independent variable, although statistical significance is far more often obtained with relative measures. The present experiment is thus no exception in this regard.

The results of this experiment indicate that the masking effect is not specific to the $555-\mathrm{nm}$ background wavelength that Thomas, Svinicki, \& Svinicki (1970) used. A surround of $576 \mathrm{~nm}$ works just as well. On the other hand, the use of a houselight is a critical factor, eliminating the masking effect entirely, thereby explaining why Baron \& Bresnahan (1969) may have failed to find masking in their study. Even without a houselight, the magnitude of the masking effect observed here was such that only a powerful within-Ss procedure would have demonstrated it. The theoretical significance of masking for the assessment of stimulus control, however, is not as limited as the magnitude of the effect observed in this study would suggest. In a recent study by Thomas, Burr, \& Eck (1970), rats were trained to discriminate between two tone-light compounds in which tone frequency differed but light intensity was held constant. In generalization testing with different light intensities, it was found that a decremental gradient could be obtained when the lights were presented alone, but not when they were paired with tones or even when tones were alternately presented during the same test session. Thus, in the Thomas, Burr, \& Eck study, masking was total, and only when this was recognized could a valid assessment of stimulus control by light intensity be made. Although masking may be minimal in some experimental situations, it may be substantial in others, and therefore the possibility of

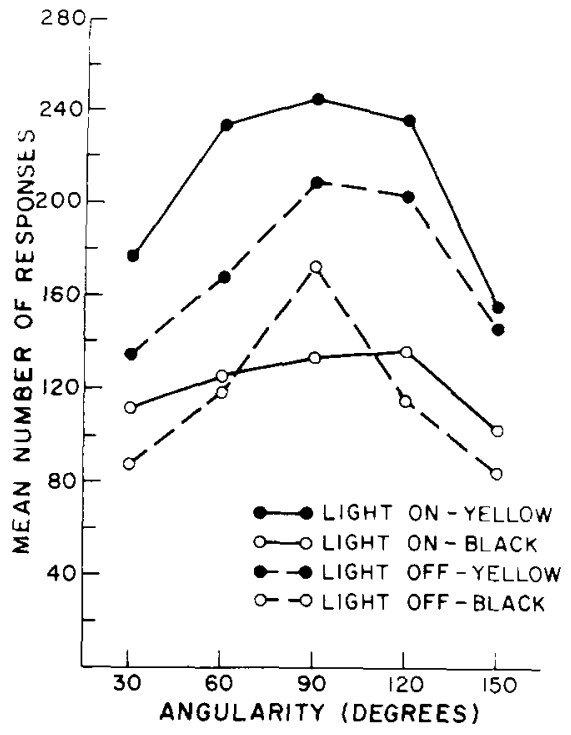

Fig. 2. Mean absolute generalization gradients of houselight-on and houselight-off groups tested under both yellow background and black background conditions.

masking must always be considered in testing for stimulus control. REFERENCES

BARON, M. R., \& BRESNAHAN, E. L Effect of chromatic surround during nondifferential training and generalization test upon generalization along the angularity dimension in pigeons. Psychonomic Science, 1969, 17 187-188.

FREEMAN, F., \& THOMAS, D. R. Attention is cue utilization in generalization testing. Paper presented at the meeting of the Midwestern Psychological Association, Chicago, May 1967.

NEWMAN, F. L., \& BENEFIELD, R. L. Stimulus control, cue utilization, and attention: Effects of discrimination training. Journal of Comparative \& Physiological Psychology, 1968, 66, 101-104.

THOMAS, D. R., BURR, D. E. S., \& ECK, $K$. O. Stimulus selection in animal discrimination learning: An alternative interpretation. Journal of Experimental Psychology, 1970.

THOMAS, D. R., FREEMAN, F. SVINICKI, J. G.. BURR, D. E. S., \& LYONS, J. Effects of extradimensional training on stimulus generalization. Journal of Experimental Psychology, 1970,83 , No. 1, Part 2.

THOMAS, D. R., \& KING. R. A. Stimulus generalization as a function of the level of motivation. Journal of Experimental Psychology, 1959, 57, 323-328.

THOMAS, D. R., SVINICKI, M. D., \& SVINICKI, J. G. Masking of stimulus control during generalization testing. Journal of Experimental Psychology, $1970,84,479-482$.

1. Personal communication from Dr. Bresnahan revealed that the designation of their background stimulus as $578 \mathrm{~nm}$ was in error. The correct designation should have been $576 \mathrm{~nm}$, as produced by Kodak Wratten Filter No. 73 with a tungsten light source. Thus, their background stimulus was the same as that used in the present experiment.

\title{
The red nucleus and visual performance in the white rat: A methodological artifact?*
}

\author{
B. MICHAEL THORNE \\ Mississippi State University, State College, Miss. 39762 \\ and \\ ROBERT THOMPSON, Louisiana State University, Baton Rouge, La. 70803
}

Albino rats, trained in a Thompson-Bryant apparatus without a choice chamber, were found to be deficient in visual discrimination performance after ventral midbrain damage. The results support previous work with rats and raise the possibility of a species difference in functional significance of the red nucleus between white rats and rhesus monkeys.

The ventral midbrain of the white rat has repeatedly been shown to be an important area for the successful retention of brightness and pattern discrimination problems (McNew, 1968; Thompson, 1969; Thompson, Lukaszewska, Schweigerdt, \& McNew,

* This research was supported in part by USPHS Grant MH08377 held by Robert Thompson.
1967). Within this area, the red nucleus has been found to be of primary importance. However, a recent attempt (Thompson \& Myers, 1971) to replicate the red nucleus work using the rhesus monkey met with unexpected results. For example, all eight monkeys with red nucleus damage displayed excellent retention of two out of three simple visual discrimination problems. 
Table 1

Error Savings Scores for Ventral Midbrain and Control Group

\begin{tabular}{llrr}
\hline Group & Lesion Locus & $\begin{array}{c}\text { S } \\
\text { Number }\end{array}$ & $\begin{array}{c}\text { Percent Error } \\
\text { Savings }\end{array}$ \\
& & 3 & 95 \\
Control & & 8 & 97 \\
& & 13 & 100 \\
& & 14 & 97 \\
& & 17 & 96 \\
Ventral & Red Nucleus & 2 & $-100+$ \\
Midbrain & Asymmetrical & 4 & 64 \\
& Red Nucleus & 5 & $-100+$ \\
& Red Nucleus & 7 & 0 \\
& Asymmetrical & 11 & 55 \\
& Subrubral & 12 & -10 \\
& Subrubral & 16 & 5 \\
\hline
\end{tabular}

With few exceptions, all of the rats receiving red nucleus damage in previous studies were trained to perform simple visual discriminations in a Thompson-Bryant ( $\mathrm{T}$ - $\mathrm{B}$ ) two-choice discrimination apparatus. The T-B apparatus requires a relatively lengthy approach response (from 14 to 20 in.) to the discriminanda, whereas this requirement is eliminated in the WGTA, in which monkeys were trained by Thompson \& Myers (1971). The possibility exists that retention deficits following red nucleus damage in the rat result primarily from motor difficulties accentuated by the lengthy approach response necessary in the $T-B$ apparatus. This procedural difference was investigated in the present experiment through the use of a T-B chamber with the choice area removed.

\section{METHOD}

The Ss were 13 adult male albino rats of the Wistar strain. Following discrimination training, eight animals were subjected to bilateral ventral midbrain lesions aimed at the vicinity of the red nucleus, while the remaining five served as unoperated controls. The subcortical lesions were made by passing anodal dc through a stainless steel electrode with $1 \mathrm{~mm}$ of the tip uninsulated. A Baltimore stereotaxic instrument was used to position the electrode.

The apparatus consisted of a two-choice discrimination box from which the choice chamber had been removed, leaving only a startbox and a goalbox. The internal dimensions of the startbox were $7 \frac{3}{4} \times 7 \frac{1}{2} \times 7$ in. A Plexiglas door separated the start area from a 3-in. grid in front of two openings into the goalbox. The openings into the goal region were blocked by $4 \times 6 \frac{1}{1} 2$ in. stimulus cards. The motive used was escape from footshock.

Preliminary training consisted of five trials in which an animal was forced to leave the start area and push aside a gray card in order to gain access to the goal region. On the day after preliminary training, training on the discrimination task (white-black problem) began. On each trial, $S$ was placed in the startbox for $5 \mathrm{sec}$, during which the Plexiglas door separating the start area from the discriminanda was lowered. After elevation of the guillotine door, $S$ was given approximately $15 \mathrm{sec}$ in which to make a choice. Choice of the black card resulted in mild footshock, while pushing the white card permitted $S$ to enter the goalbox. The position of the cards was varied according to a double alternation sequence, and the correction technique was used. Animals were given eight trials per day until a learning criterion of 15 correct responses in 2 consecutive days was attained.

After a 2-week recovery period, retention testing began and consisted of relearning the original problem. Savings scores based upon the number of errors made prior to a criterion run were calculated for each animal. Animals performing at a chance level after making twice as many errors as in original learning were terminated.

At the conclusion of retention testing, histological verification of lesion placements was made.

$$
\text { RESULTS }
$$

Histological analysis revealed that all except two animals (Ss 4 and 11) had bilaterally symmetrical, well-placed ventral midbrain lesions. The primary focus of damage in Ss 2 , 5 , and 7 was the red nucleus, while the remaining animals with symmetrical lesions (Ss 12, 16, and 22) suffered damage mainly to the subrubral area, including the medial portion of the substantia nigra. All six animals had damage to structures found by Thompson (1969) to be crucial for retention of visual discrimination tasks. Most of the lesioned animals exhibited transient feeding and motor difficulties. In addition, four animals (Ss 2, 7, 16, and 22) had response difficulties (i.e., either running too fast or too slow) during postoperative training.
Upon examination of savings scores in Table 1 , it can be seen that ventral midbrain damage severely disrupted performance on the W-B discrimination. A Mann-Whitney test was performed on the savings scores for the two groups and resulted in a significant difference $(\mathrm{U}=0$, $\mathrm{p}=.001$ ).

Despite the ease with which the discrimination was acquired in original learning, three Ss $(2,5$, and 22) were sacrificed after making more than twice the errors made preoperatively. Of these, two (2 and 5) had red nucleus lesions, while $\mathrm{S} 22$ suffered subrubral damage. In fact, $S 5$ had the largest, most well-placed lesion of the group. In spite of this damage, the animal performed very well postoperatively, running at a normal speed, while requiring little shock.

\section{DISCUSSION}

Performance on a brightness discrimination was disrupted by ventral midbrain damage, despite the elimination of the requirement of a lengthy approach to the discriminanda. Thus, the present study adds further support to the results reported by McNew (1968), Thompson (1969), and Thompson et al (1967) concerning the functional importance of the ventral midbrain of the rat for visual discrimination.

The results do not support the hypothesis that retention losses seen in ventral midbrain-lesioned $S s$ result from motor deficits accentuated by the approach response required in the T-B apparatus. Rather, evidence is provided for a species difference between the white rat and the rhesus monkey in terms of functional organization of the ventral midbrain. However, further investigation of procedural differences (e.g.: differences in motivation) between previous work on the rat and the rhesus monkey study reported by Thompson \& Myers (1971) will be necessary before definitive conclusions can be drawn.

\section{REFERENCES}

McNEW, J. J. Role of the red nucleus in visually guided behavior in the rat Journal of Comparative \& Physiological Psychology, 1968, 65, 28 2-289.

THOMPSON, R. Localization of the "visual memory system" in the white rat. Journal of Comparative \& Physiological Psychology, Monograph Supplement, $1969,69,1-29$.

THOMPSON, R., LUKASZEWSKA, I. SCHWEIGERDT, A., \& MCNEW, J. J. Retention of visual and kinesthetic discriminations in rats following pretecto-diencephalic and ventral mesencephalic damage. Journal of Comparative \& Physiological Psychology, $1967,63,458-468$.

THOMPSON, R.. \& MYERS, R. E, Brainstem mechanisms underlying visually guided responses in the rhesus monkey. Journal of Comparative \&

Physiological Psychology, Monograph Supplement, 1971 , in press. 